\title{
Empirical Assessment of the Reputational Impact Capital on Investment Activity
}

\author{
Elshin L.A. \\ Department of Economics \\ University of management "TISBI" \\ Kazan, Russia \\ Leonid.Elshin@tatar.ru
}

Safina L.G.

Department of Economics

University of management "TISBI"

Kazan, Russia

lsg2103@mail.ru

\author{
Gerasimova O.E. \\ Department of Economics \\ University of management "TISBI" \\ Kazan, Russia \\ olgagerasimova77@mail.ru
}

\author{
Murtazina G.R. \\ Department Finance and Credit \\ University of management "TISBI" \\ Kazan, Russia \\ gulamur@mail.ru
}

\begin{abstract}
As it is clear from practice and empirical observations, the reputation activity of economic agents causes the whole set of perspectives of their development by sustained positive or, on the contrary, by negative expectations of the partners interacting with them concerning opportunities of their own development both in tactical, and in institutional directions. In this regard the reputation is very important and gets wide circulation in a research field. Meanwhile it should be noted that studying of this question in the sphere of scientific works and researches finds the reflection, mainly, at the microlevel, concentrating the attention to assessment of reputation activity of economic entities. At the same time the research of the reputation capital and its influence on development of regional Inational economic systems is unfairly deprived of attention. In this regard, aiming to improve this defect, the index dynamics of the reputation capital is revealed in the article on the basis of the developed methodical approaches to the formalized assessment of reputation of the territory of the Republic of Tatarstan and main components which determine its level. It allowed, using methods of econometric modeling, to implement reputation impact assessment on investment activity of the region. In particular, being guided by the principles and instruments of regression analysis and also relying on a method of fictitious variables, the high level of interrelation is implemented between the studied indicators in view of the found essential level of elasticity between the analyzed indicators.
\end{abstract}

Keywords-reputation capital of the region; reputation economy; investment activity; resources of development of the region; business activity; quantitative assessment of reputation of the region; globalization; factors of economic growth; econometric modeling; method of fictitious variables.

\section{INTRODUCTION}

Modern economy is characterized by the diversity of institutions that quantify its development. It requires a wide range of methods to identify the factors that generate its dynamics. It's necessary to understand that the traditional factors of economic growth inherent in neoclassical, neoceinsian, non-institutional and other traditional schools of economic thought are not always able to explain the transformations that are taking place in the emerging multidimensional economy. In this regard, it is necessary to expand the research range, which includes, in addition to classical production factors, also not traditional, but also play a significant role in modern economic conditions.

At the same time the fact that inclusion of wide number of predictive indicators (predikators) into the system of production functions is important because as a result the risks can be predicted by the statistical and mathematical certainty of the constructed models. In this connection, on one hand, involving of such factors which are considered as modern processes of macroeconomic development taking into account globalization of economic processes is required. On the other hand, the quantity of the used factors is important in models which corresponded to the necessary criteria, both in terms of representativeness and in terms of methods of the mathematical analysis.

\section{LITERATURE REVIEW}

To our opinion, one of the main trends of the last decades predetermining structural and economic transformations of national/regional economic systems is globalization of the economic processes integrated into a uniform world chain of creation of added value. It forms special institutional settings 
of their development. The reputation capital of territories forming representations of economic agents in the sphere of strategic behavior models creation on the basis of the generated expectations becomes the major factor in these conditions defining macroeconomic generation. In this regard it is possible and necessary to refer to category of the major factors defining dynamics and quality of economic growth of national economies within the formed global competitiveness.

Foreign researchers have similar views $[1 ; 2 ; 3 ; 4 ; 5 ; 6]$, as well as Russian scientists implement the research of intangible factors of production in the system of economic development $[7,8,9]$. Their research predominantly reveals both the conceptual apparatus itself and the substantive characteristics of categories such as reputation and image and their distinctive features. It is important to note that the research range is primarily limited by qualitative analysis methods. Meanwhile, an important research component, such as modeling of studied processes using quantitative analysis techniques, is insufficiently disclosed and remains outside the research range.

Table 2 shows the main approaches and methods for measuring reputational capital in the concentrated form.

TABLE I. BASIC APPROACHES AND METHODS FOR MEASURING REPUTATIONAL CAPITAL

\begin{tabular}{|l|l|l|}
\hline № & Method/author & \multicolumn{1}{c|}{ Framework of methodological tools } \\
\hline 1 & Ex-index & $\begin{array}{l}\text { Determines the level of reputational capital of a } \\
\text { business entity based on the measurement of the } \\
\text { level of tonality and popularity of reputational } \\
\text { requests [10] }\end{array}$ \\
\hline 2 & $\begin{array}{l}\text { M. Arslan и S. } \\
\text { Seker }\end{array}$ & $\begin{array}{l}\text { The methodological approach is based on the } \\
\text { process of determining the popularity in the global } \\
\text { information environment of key parameters } \\
\text { characterizing the efficiency of the organization } \\
\text { the study is tested on the example of Turkish } \\
\text { higher education institutions) [11] }\end{array}$ \\
\hline 3 & $\begin{array}{l}\text { Hossein Shad } \\
\text { Manaman, } \\
\text { Jamali, Abolfazl } \\
\text { AleAhmad }\end{array}$ & $\begin{array}{l}\text { The reputation capital of firm is measured on the } \\
\text { basis of assessment of the so-called "social proofs" } \\
\text { creating the reputation capital of economic entity. } \\
\text { The algorithm is based on measurement of } \\
\text { frequency of generation and tonality of responses } \\
\text { of consumers on the social networks creating a } \\
\text { basis for identification of a positive or negative } \\
\text { image of the studied companies [12] }\end{array}$ \\
\hline 4 & $\begin{array}{l}\text { Yi Grace Ji, } \\
\text { Cong } \\
\text { Michael Northc, } \\
\text { Jiangmeng Liu }\end{array}$ & $\begin{array}{l}\text { Similar methods of measuring reputation are used } \\
\text { as in the previous method (№3) [13] }\end{array}$ \\
$\begin{array}{l}\text { Peter Dorčák, Markovič, } \\
\text { František } \\
\text { Pollákb }\end{array}$ & $\begin{array}{l}\text { The reputation and popularity of a firm in a global } \\
\text { information environment is determined based on } \\
\text { the tonality of search queries about the object } \\
\text { under investigation - as the difference between } \\
\text { positive and negative reviews [14] }\end{array}$ \\
\hline 5
\end{tabular}

In general, the overview of methodological approaches for the evaluation of economic agents' reputation is very close to the determination of levels of tonality of a news background about an object of a research and frequency of generation of news on social networks and the Internet space. At the same time all of them concentrate the attention only on an object of a research which is the firm itself.
Unfortunately, work revealing formalized methods of assessing reputational capital at the micro- and macro-level are practically not found in the research sphere. Such works are either limited to qualitative analysis of the subject and objects of the study, or limited, for example, to methods of analysis such as sociological research, expert assessments, etc.

At the same time, as it was noted earlier, use of the instruments based on objective research of data with application of mathematical and stochastic methods essentially increases reliability of the received conclusions because of decrease of lthe subjective level when carrying out research works and analytical evaluation.

Apparently, the reflection within projection of the algorithms considered above in relation to the studied objects meso - and macrolevel could find the solution of the problem. However, this approach would contain a number of methodological inaccuracies because of more "difficult architecture" of regional/national economic systems. It is connected with the fact that the reputation of the firm in information space is based only on the data of a news background and its intensity revealing features and the prospects of the current and perspective functioning of firm in the sphere of economic development. In other words, an external environment, as a rule, does not interested in features of functional development of the company because the major component is functioning resulting efficiency for a certain period of time which shows the prospects of its development, and, therefore, prospects of reputation activity data of an economic base.

Meanwhile, the reputation capital of regional economic systems has to be based on wider range of the factors containing parameters of both tactical and institutional order. In our opinion, evaluation of the region' reputation on the basis of continuous monitoring of not classified wide massif of details on the basis of comparison of negative and positive information, will result in incorrect results. It is connected with the fact that structure of information, its profile, sources of generation form various level of a deposit to reputation of the region, and, therefore its competitiveness in connection with its more difficult architecture of management and development. In this regard development of the methodological approaches directed to the evaluation of reputation capital of regional systems is represented necessary and extremely relevant. At the same time mentioned instruments have to include a set of the mechanisms allowing to classify structure of the analyzed information in the global media space and also in space of social networks taking into account that they form the corresponding reputation. Moreover, it is obviously important that determination of the weight coefficients which show the level of the deposit based on the uniform principle of the corresponding profiles of information space and on the change of the region reputation. It will allow not only to determine the level of reputation of regional activity in more structured form, but also to perform factor analysis on the basis of the grouped data.

Finally realization of this sort of methodological instruments will promote essentially the solution of such important question of the economic theory as evaluation of 


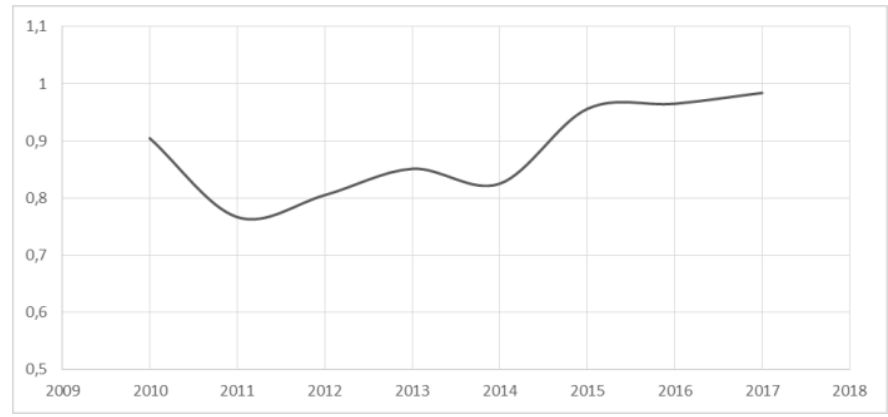

A key feature of the present study is the proposed version of the conceptual approach to quantification of reputational capital of the territory, which allows to make a transition from qualitative assessments of the development of the investigated process and its impact on key parameters of macroeconomic development, to formalized, based on the application of methods of economic and statistical modeling.

Based on the developed methodological tools for quantitative assessment of reputational capital of the region, previously detailed in the published works of the authors [15], its dynamics for the period from 2013 to 2017 was evaluated (on the example of the Republic of Tatarstan). In a concentrated form, the concept of determining the reputational capital index is based on the design of a series of subindexes characterizing the reputational activity of the Territory in the global information space. This approach is based on methods of constructing and quantifying the institutional and market environment assessed by economic agents, reflected in the system of information estimates dynamically generated in the global information space. Their fixation makes it possible to determine the fundamental level of expectations of economic agents about the prospects and quality of socio-economic development of the object of research.

The reputation of the region is assessed on the basis of 5 key subindexes (Figure 1).

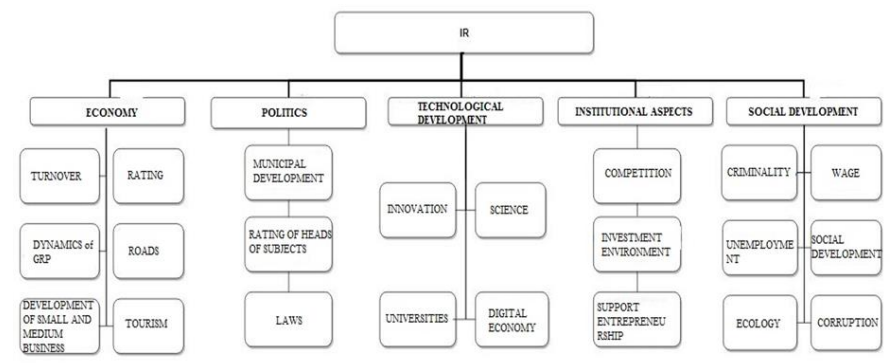

Fig. 1. System of search queries, forming representations (image) about reputation of territory (region)

\section{RESULTS}

Thus, integral values of reputational capital index for the Republic of Tatarstan for the period from 2010 to 2017 were obtained based on the described tools, as a result of implemented evaluations and calculations. (Figure 2).
Fig. 2. Dynamics of the reputation capital of the Republic of Tatarstan (IPK)

The implemented evaluations dynamics allow to pass the components "Index of the Reputation Capital of the Territory" to the major investigation step - identification of interrelation between the level of reputation of the region and parameters of its social and economic development. Methods of econometric modeling are selected as tools where "index of the reputation capital" is considered as an exogenous variable, and investment into fixed capital is considered as an endogenous variable. The model (1) is constructed relying on the instruments of the implemented regression analysis.

$$
\mathrm{I} \%=-1,32+0,59 \mathrm{IPK}+1,52 \mathrm{~F} 1+1.05 \mathrm{~F} 2
$$

I\% - Fixed investment growth rate, $\%$ of previous year;

IPK - Integral index of reputational activity of the region;

F1, F2 - fictitious variables.

The received parameters characterizing the statistical importance of the received regression model with two fictitious variables are shown by its very high level to reliability $(\mathrm{R} 2=0,81$; criteria - Values are less than the specified significance level 0,05).

The estimates and calculations presented demonstrate a high level of verification of the built model. This makes it possible to form an evidence base that there is a clear dependence between the level of reputational activity of the region and the parameters of its social and economic development.

\section{DISCUSSION}

Thus, the reputational economy is an instrument that contributes to strengthening the competitive environment in interregional space. In conditions of strict resource restrictions, high level of competition between regions for attracting new residents - economic entities to the territory, reputational activity, as the implemented evaluations show, is a very effective tool in competition. However, it would undoubtedly be a mistake to rely entirely on such an instrument of regional governance. It must be clearly stated that reputational capital plays more supportive role. At the same time, the importance of this role is significant and can intensify the dynamics of real processes in the economy.

\section{CONCLUSIONS}

In general, it should be noted that reputational capital, according to the obtained calculations, plays a prominent role 
[8] Pankrukhin A.P. "Best cities for business." How much Forbes managed to assess the convenience of Russian cities. Corporate imageology. 2008, 3, pp. 76 - 77.

in the process of social and economic development of the regions. Possessing special means and methods capable of positively influencing the level of reputational capital of the territory, additional tools and opportunities are being opened for intensification of regional socio-economic development.

Thanks: the publication was prepared within the framework of the scientific project No. 19-010-00211 supported by RFFI.

We express our gratitude for the preparation of the article to the team of authors of the scientific draft of the RNF (draft No. 19-18-00202).

\section{References}

[1] Roberts, P. W., \& Dowling, G. R. Corporate reputation and sustained superior financial performance. Strategic Management Journal. 2002, 23(12), pp. 1077-1093.

[2] Raithel, S., \& Schwaiger, M. The effects of corporate reputation perceptions of the general public on shareholder value. Strategic Management Journal. 2014, 36(4), pp. 945-956. URL: http://dx.doi.org/10.1002/smj.2248

[3] Shamsie, J. The context of dominance: An industry-driven framework for exploiting reputation. Strategic Management Journal. 2003, 24(3), pp. 199-215. DOI: http://dx.doi.org/10.1002/smj.291

[4] Fombrun, C., \& Shanley, M. What's in a name? Reputation building and corporate strategy. Academy of Management Journal. 1990, 33(2), pp. 233-258,

[5] Hall, R. A framework linking intangible resources and capabilities to sustainable competitive advantage. Strategic Management Journal. 1993, 14(8), pp. 607-618.

[6] Roberts, P. W., \& Dowling, G. R. Corporate reputation and sustained superior financial performance. Strategic Management Journal. 2002, 23(12), pp. 1077-1093.

[7] Vazhenina I.S. The conceptual basis for the formation and improvement of the reputation of the region. Regional economy: theory and practice. 2007, 8, pp. $91-102$
[9] Korchagin P.V. Economic and social development of the territory: methodological and applied aspects. The thesis for a degree of the Doctor of Economics. Tolyatti state university of service. Tolyatti: Volga region state university of service. 2012, pp. $91-102$.

[10] Online Reputation Index. Wikipedia. URL: https://ru.wikipedia.org/wiki/\%D0\%98\%D0\%BD\%D0\%B4\%D0\%B5\% D0\%BA\%D1\%81_\%D0\%BE\%D0\%BD\%D0\%BB\%D0\%B0\%D0\%B9 $\% \mathrm{D} 0 \% \mathrm{BD}-$

$\% \mathrm{D} 1 \% 80 \% \mathrm{D} 0 \% \mathrm{~B} 5 \% \mathrm{D} 0 \% \mathrm{BF} \% \mathrm{D} 1 \% 83 \% \mathrm{D} 1 \% 82 \% \mathrm{D} 0 \% \mathrm{~B} 0 \% \mathrm{D} 1 \% 86 \%$ $\mathrm{D} 0 \% \mathrm{~B} 8 \% \mathrm{D} 0 \% \mathrm{~B} 8$.

[11] Mehmet Lutfi Arslan and Sadi Evren Seker Web Based Reputation Index of Turkish Universities. International Journal of e-Education, eBusiness, e-Management and e-Learning. 2014, vol. 4, 3, pp. 197-203. URL: https://docplayer.net/8905723-Web-based-reputation-index-ofturkish-universities.htm

[12] Hossein Shad Manaman, Shahram Jamali, Abolfazl AleAhmad. Online reputation measurement of companies based on user-generated content in online social networks. Computers in Human Behavior. 2016, 54, pp. 94-100

[13] Yi Grace Ji, Cong Li, Michael Northc, Jiangmeng Liu. Staking reputation on stakeholders: How does stakeholders' Facebook engagement help or ruin a company's reputation?. Public Relations Review. 2017, 43, pp. 201-210

[14] Peter Dorčák, Peter Markovič, František Pollákb. Multifactor analysis of online reputation of selected car brands. TRANSCOM 2017: International scientific conference on sustainable, modern and safe transport. Procedia Engineering. 2017, 192, pp. 719 - 724

[15] Alexsandr S. Kuznetsov. Russian Professor's meeting. Russian Journal of Physical Education and Sport. 2019, 14(1), pp. 17-22. DOI: DOI 10.14526/2070-4798-2019-14-1-18-24

[16] Grunichev A. S., Elshin L.A. Reputational economy: new paradigm of economic growth research. Theoretical and applied economy. 3. DOI: 10.25136/2409-8647.0.0.30499. 